\title{
Hybrid IWOPSO optimization based marine engine rotational speed control automatic system
}

\author{
Ahmed Samawi Alkhafaji ${ }^{1}$, Abdulrasul A. Al-hayder ${ }^{2}$, Ali Shaban Hassooni ${ }^{3}$ \\ ${ }^{1,2}$ Department of Electrical Engineering, University of Babylon, Iraq \\ ${ }^{3}$ Department of Biomedical Engineering, University of Babylon, Iraq
}

\begin{tabular}{l} 
Article Info \\
\hline Article history: \\
Received May 12, 2019 \\
Revised Sep 5, 2019 \\
Accepted Sep 27, 2019 \\
\hline Keywords: \\
Engine rotational speed control \\
system \\
Hybrid IWOPSO \\
Main diesel engine \\
PID
\end{tabular}

Corresponding Author:

\begin{abstract}
Transporting industry is having an important influence on the nations' progress. The states that having long shoreline are taking advantage of their locations in using sea transportations which is more economical than other types of transportations. One of the most economical marine transport is the diesel fueling engines. This paper is to optimize the PID controller to control the speed of the engine overcoming the navigation environmental changes such as waves, winds and other effective external factors as well as the vessel internal changes such as the shipment load, equipment's conditions etc. PID is optimized through the optimum selection of its parameters (KP, KI and KD). A Simulink/MatLab model of the system is designed for this purpose. The Hybrid IWOPSO (HIWOPSO) algorithm is used for finding the optimum values of the PID parameters. The engine step response with these parameters is compared to the responses with those obtained by the IWO and PSO besides the Fuzzy Logic Control (FLC).
\end{abstract}

Copyright (c) 2020 Institute of Advanced Engineering and Science. All rights reserved.

\author{
Ahmed Samawi Alkhafaji, \\ Department of Electrical Engineering, \\ University of Babylon, \\ Babylon, Iraq. \\ Email: ahmed.samawi2019@gmail.com
}

\section{INTRODUCTION}

In order to maintain a constant marine thrust, the main engine rotational speed needs to be kept constant despite the marine vessel load and navigation environments. This is normally accomplished by using automatic controller. The controller's parameters need to be an optimal to get a trusted, reliable, efficient, economical and fast responding vessel at all working conditions. Since the engine rotational speed is proportional with the fuel amount feeds to the engine cylinders, the speed control therefore shall be done by controlling the fuel flow $[1,2]$. The investigated system working principles were studied by the authors and a PID type controller is used. The core of this work is to determine the controller parameters to get the optimal behavior of the system [3]

The famous "ZN" Ziegler-Nichols method of PID optimization is using the open-loop and closedloop responses checkup of the plant which is shown in $[4,5]$. It is experiencing unnecessary overshot of the plant response. $\mathrm{ZN}$ is very complicated and difficult to be used to solve a controlling problem in complicated systems such as the marine diesel fuel engine that this work is dealing with. After the advanced progress in computations machines; numerical optimization method is becoming easy to be used to adjust the PID parameters passing the negative aspects of the conventional methods. The difficulties of controlling the marine engine rotational speed is becoming able to be solved by using this concept [3].

Years ago, many swarming principles were widely used to optimize the PID controller. In the 19911992, the (ACO) Ant Colony Optimization was adopted for the first time by M. Dorigo and colleagues who were stimulated by nature to produce a mathematical simulation for solving tough combinatorial optimization 
issues [6, 7]. Farooq and others [8] were inspired by the bee method of communication and developed an algorithm for "routing in telecommunication networking". Particle Swarm Optimization (PSO) technique was presented by Eberhart and Kennedy [9] after their study of the birds teeming and fish learning strategies. A new computation algorithm, the Invasive Weed Optimization was introduced in 2006 by Mehrabian and Lucas [10].

This work is using a newly developed numerical algorithm (HIWOPSO) to optimize the PID parameters. This algorithm is a combination of both PSO and IWO by taking some of the characteristics of each one and applied them in the new HIWOPSO [11]. The obtained results are evaluated against that are obtained by the two original algorithms (IWO and PSO) as well as the widely used modern (FLC) technique. The leading criteria used to evaluate the numerical techniques is the "square-error-integral" criteria [12-14].

This article is consisting of five sections. Section one of this article is this introduction. The marine diesel engine rotational speed control system is explained in section two while section three is providing an introduction of the IWO/PSO algorithm and tactic used to set the algorithm parameters as well as a quick review of PSO and IWO algorithms. In section four, a Simulink model of the system is constructed and different PID controller tuning algorithm as well as the Fuzzy Logic Control are applied. The work is concluded in section five

\section{MARINE DIESEL ENGINE ROTATIONAL SPEED AUTOMATIC CONTROL SYSTEM}

The engine is maintained at a desired speed despite disturbances (such as changing in load) effecting the marine vessel is accomplished by controlling the fuel flow into its cylinders. A governor is utilizing this function by a continuous repositioning the fuel pump racks. There are several types of governors; mechanical, hydraulic and electrical governors $[1,2,15,16]$. The mechanical governor, shown in Figure 1, is composed of two balls fitted on a main spindle through arms in such way to give them a free readily movement. A sleeve is connected to the arms at the ends far from the spindle through two links which is moving vertically according to the balls' movement. Attached to this sleeve is a fuel regulating valve that moves according to the movement of sleeve.

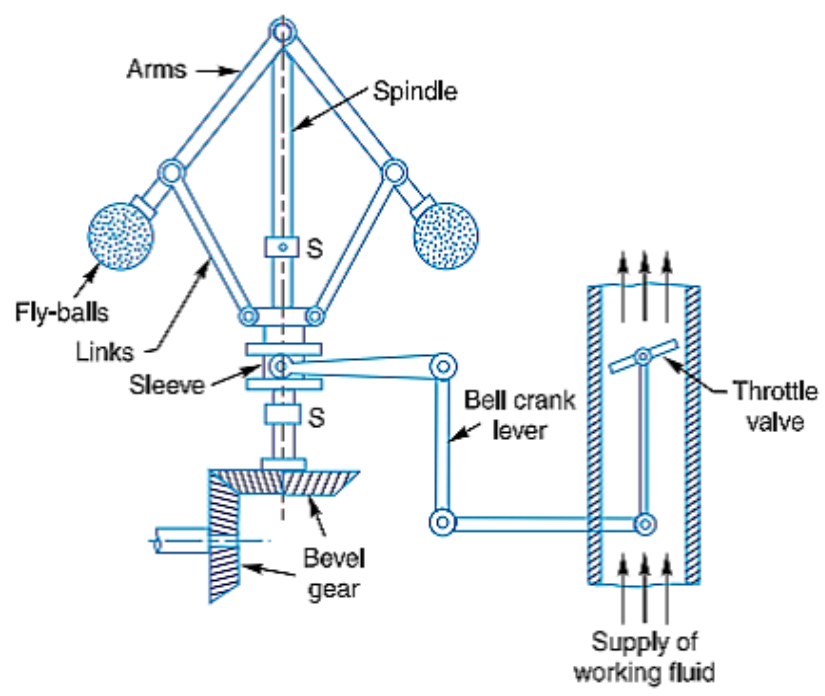

Figure 1. Principle of mechanical governor [16]

The hydraulic governor is represented in Figure 2. It is controlling the fuel valve opening by the oil pressure changes which is controlled by the hydraulic governor. The governor sleeve is connected to an oil actuating piston. The sleeve movement is changing the pressure on the transmitting piston and therefor the oil pressure is changing according to the piston position. The most accurate and reliable governor is the electrical one Figure 3. It is consisting of rectifier, controller and amplifier. The camshaft of the engine is interlocked to an alternator which is produces an electrical current proportional to the engine speed. This current is rectified into DC current. The current is then amplified and compared to the set value which representing the required rotational speed of the engine. The error signal produced by the comparator is controlling the fuel valve and hence the fuel flow into the engine to get the required speed $[1,2,15,16]$.

Hybrid IWOPSO optimization based marine engine rotational speed control ... (Ahmed Samawi Ghthwan) 


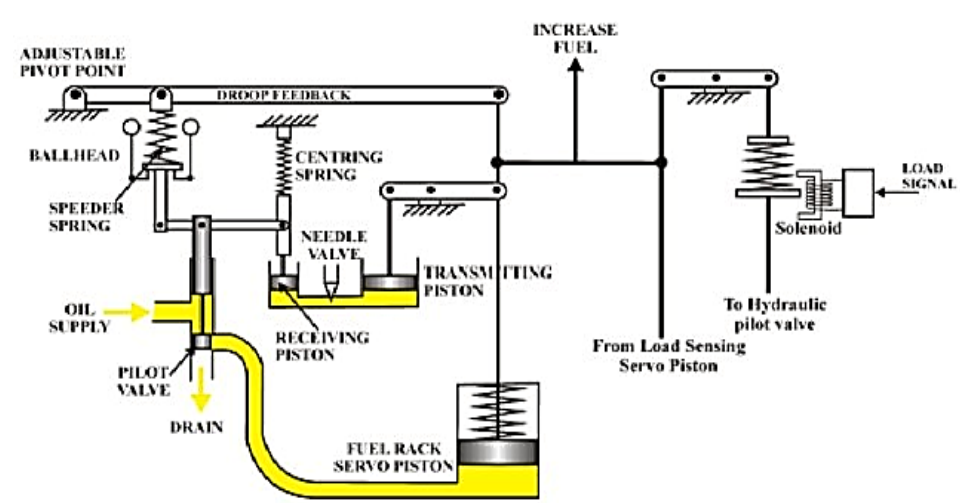

Figure 2. Principle of hydraulic governor [16]

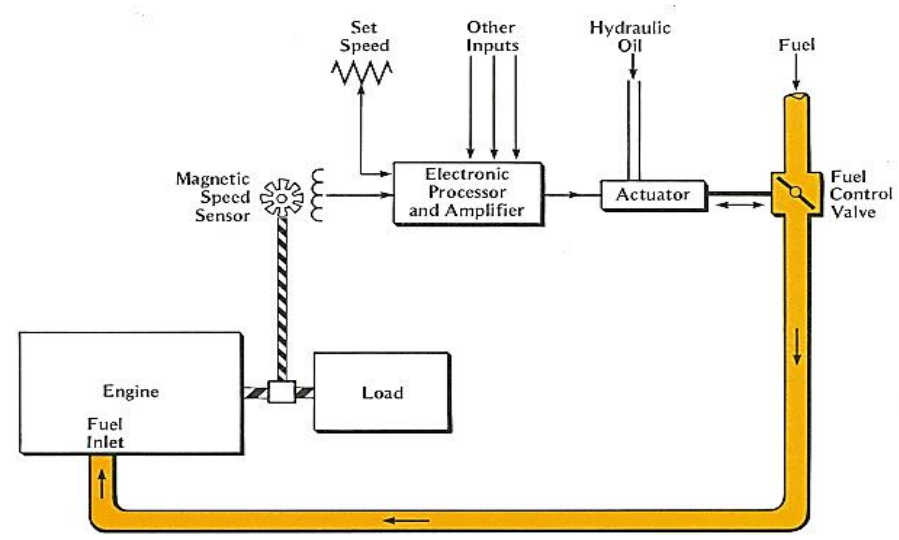

Figure 3. Electric governor [16]

\section{DESIGN ALGORITHMS}

\subsection{Particle swarm optimization (PSO)}

PSO were published for the first time in 1995 by Kennedy and Eberhart [9, 17]. It is mimic by how the birds communicate to grouping and foraging during their flaying. It is tracking the position and velocity of a moving particle [9, 18, 19]. The (1) and (2) are representing the next particle's velocity and position $[11,4]$.

$$
\begin{aligned}
& V_{i}(t+1)=\omega V_{i}(t)+c_{1} * \varphi_{1} *\left(P_{i}(t)-X_{i}(t)\right)+c_{2} * \varphi_{2} *\left(P_{g}(t)-X_{i}(t)\right) \\
& X_{i}(t+1)=X_{i}(t)+V_{i}(t+1)
\end{aligned}
$$

Where $P_{i}$ representing the particle best current position and $P_{g}$ is the position of the best particle in the whole swarm of the current iteration. The learning factors $c_{1}$ and $c_{2}$ are constants. They are determining the balance between acceleration toward local best (individual's experience, cognition, exploration) or global best (social collaboration or interaction, exploitation). $\varphi 1$ and $\varphi 2$ are arbitrary numbers between $[0,1] . \omega$ is an inertia mass which is limited between $\left[-V_{\max }, V_{\max }\right]$ and determines the impact of velocity memory and is servicing on global or local search [11, 20-22]. It is also suggested to restrict the velocity to a specified range [- $\left.V_{\max }, V_{\max }\right][10,11,20-22]$. Several forms of PSO, as well as swarm techniques, were introduced, with a continuous upgrading. The forms are differing in the operators choosing of the equations [11, 20].

\subsection{Weed optimization (IWO)}

Mehrabian and Lucas (in 2006) introduce this optimization technique [19]. This technique is numerically adopting the weeds naturally colonizing and replanting. IWO performance is characterized by its way of regeneration, distribution and modest elimination from other nature's simulation algorithms [10, 
11, 20, 23-25]. IWO is initiated by an arbitrary generated initial population in the working domain. Seeds shall be generated by the members of initiated population according to their relative qualifications. This is meaning that each affiliate starting with $S_{\min }$ of seeds for the poorest member and growths linearly to $\mathrm{S}_{\mathrm{max}}$ for the greatest member. The produced seeds are arbitrarily scattered in the determined working area in a normal distribution numbers such that the mean is zero and with the adaptive standard deviation (SD) then the new SD $\left(\sigma_{\text {iter }}\right)$ for the current generation is calculated as in $(3)[11,20]$.

$$
\sigma_{\text {iter }}=\frac{\left(\text { iter }_{\text {max }}-i t e r\right)^{n}}{\left(\text { iter }_{\max }\right)^{n}}\left(\sigma_{\text {final }}-\sigma_{\text {initial }}\right)+\sigma_{\text {final }}
$$

Where iter $_{\max }$ is the maximum number of iterations and $\mathrm{n}$ is the nonlinear modulation index. The new generated seeds together with their parents are taken as a possible solution for the following generation. A segregation processes is then executed according to the seeds' qualifications; the non-qualified seeds and their parents shall be eliminated. The above-mentioned steps of the algorithm shall be repeated till reaching the maximum population and by checking the qualifications and applying the elimination, the qualified seeds with their parents will be a regenerative seed $[11,20]$.

\subsection{The hybrid IWO/PSO algorithm (HIWOPSO)}

It is clear from the above two sections (A \& B) that IWO and PSO are two different optimizations techniques. Here, a hybrid IWO/PSO algorithm (HIWOPSO) is introduced. It is started with the colonization as in IWO but the PSO equations are used to the seeds repositioning. This process is executed firstly by regenerating the seeds and then the new velocity is calculated using (4) while the new location is calculated by (5). The seeds are then arbitrarily scattered in the Sam procedure of IWO for the following population. The pseudo-code of this algorithm is in $[11,20]$. The random distribution step still an important step of the hybrid algorithm. An earlier work is showing the importance of having this step in the algorithm in order to get an adequate rate of achievements $[11,20]$.

$$
\begin{aligned}
& V_{i}(t+1)=\omega V_{i}(t)+c_{1} * \varphi_{1, s} *\left(P_{i}(t)-X_{i}(t)\right)+c_{2} * \varphi_{2, s} *\left(P_{g}(t)-X_{i}(t)\right) \\
& X_{i, s}(t+1)=X_{i}(t)+V_{i, s}(t+1)
\end{aligned}
$$

" $V_{i, s}$ and $X_{i, s}$ are the next particle velocity and position for the $\mathrm{s}_{\mathrm{th}}$ seed of the $\mathrm{i}_{\mathrm{th}}$ member" $\mathrm{C}_{1}$ and $\mathrm{C}_{2}$ named learning Factors, are usualle constants.

\section{DESIGN OF THE AUTOMATIC CONTROL SYSTEM MODEL OPTIMIZED PID CONTROLLER}

\subsection{Conventional PID (proportional-integral-derivative) controlle}

The speed of the internal combustion engine is needs to be controlled. Needs to be optimized to overcome the influence of the load and external environments changes on the engine speed. A simulation model of the engine speed automatic control system was constructed for this purpose. The relationship between the system's input and output parameters were deduced. An optimization of PID controller algorithm is a translation of the linguistic control policy of the experts' knowledge into an automatic control strategy [3]

The goal of this work is to examine the behavior of the system when a hybrid IWO/PSO optimization algorithm is used for PID parameters tuning. The optimization criteria are to achieve globally minimal squared error integral and minimum overshoot in the step response of the system. The PID tuning parameters are the proportional gain $\left(K_{P}\right)$, integral gain $\left(K_{I}\right)$ and the differential gain $\left(K_{D}\right)$. The $(6)$ is showing the controller transfer function.

$$
G(s)=\frac{U(s)}{E(s)}=k_{P}+\frac{k_{I}}{s}+k_{D} S
$$

Where

$$
\begin{aligned}
& K_{P} \text { : proportional gain } \\
& K_{I}: \text { integral gain } \\
& K_{D} \text { : differential gain } \\
& E(s) \text { : Laplace transform of the input to the controller } \\
& U(s) \text { : Laplace transform of the output of the controller }
\end{aligned}
$$


Conventional PID controller's parameters are chosen by approximations and trial and error methods which is not guarantee an optimal result. The performance specifications of the system's step response such as rise time, overshoot, settling time and steady-state error can be improved by tuning the PID controller parameters $\left(K_{P}, K_{I}\right.$ and $\left.K_{D}\right)$. Each one of these parameters is responsible for one or more of the system's behavior specifications [16]. Using the modern control algorithms IWO, PSO \& HIWOPSO for optimizing the controller and hence the system behavior is fasting and more reliable than the conventional techniques.

\subsection{Mathematical model of marine diesel engine system}

The marine engine speed (the plant) is controlled by a fuel amount that flow into it. This fuel flow is controlled by a governor which is controlled by a DC current servomotor (the actuator) which is of a second order transfer function [15], (7).

$$
\frac{H(S)}{H_{g}(S)}=\frac{\omega_{n d}^{2}}{S^{2}+2 \zeta_{n d} \omega_{n d} S+\omega_{n d}^{2}}
$$

$\mathrm{Hg}(\mathrm{S})$ is the level of the required opening of fuel oil throttle. $\mathrm{H}(\mathrm{S})$ is the actual opening of fuel oil throttle. $\omega_{\text {nd }}$ is the natural frequency of the servo motor (actuator). $\zeta_{\text {nd }}$ is the damping coefficient of actuator which is between 0.4 and 0.8 . The differential equation of marine diesel engine without turbocharger is:

$$
T_{a} \frac{d y(t)}{d t}-y(t)=\eta(t-\tau)-\lambda(t)
$$

Where, $y(t)$ is the rotation speed of marine diesel engine, $\eta(t)$ is the opening level of fuel oil throttle, $\lambda(t)$ is disturbance, $T_{a}$ is the time constant of marine diesel engine and $\tau$ is the time delay of fuel throttle opening [15]. The (9) is the Laplace transform of (8).

$$
\frac{Y(S)}{e^{-\tau S_{H}(S)-\lambda(S)}}=\frac{1}{T_{a} S+1}
$$

$\mathrm{Y}(\mathrm{S})$ and $\mathrm{H}(\mathrm{S})$ are the Laplace transform of $\mathrm{y}(\mathrm{t})$ and $\eta(\mathrm{t})$ respectively, $\lambda(\mathrm{S})$ is the Laplace transform of $\lambda(\mathrm{t})$. The TF of the engine with the activation of turbocharger is as in (10) [15].

$$
\frac{Y(S)}{e^{-\tau S_{H}(S)-\lambda(S)}}=\frac{\omega_{n}^{2}}{S^{2}+2 \zeta_{n} \omega_{n} S+\omega_{n}^{2}}
$$

$\omega_{\mathrm{n}}$ and $\zeta_{\mathrm{n}}$ are respectively the non-damping natural frequency and the damping factor of the marine diesel engine. The (11) is the entire system (with a turbocharger) TF without disturbance [15]. This equation is representing the Process which is a combination of the actuator (servo motor) and the plant (diesel engine).

$$
\frac{Y(S)}{H_{g}(S)}=\frac{\omega_{n d}^{2}}{S^{2}+2 \zeta_{n d} \omega_{n d} S+\omega_{n d}^{2}} \cdot \frac{\omega_{n}^{2}}{S^{2}+2 \zeta_{n} \omega_{n} S+\omega_{n}^{2}} \cdot e^{-\tau S}
$$

\subsection{Diesel engine speed regulation model based on the optimization of PID controller}

The PID controller parameters $\left(K_{P}, K_{I}\right.$ and $\left.K_{D}\right)$ shall be derived using the above mentioned algorithms (IWO, PSO and HIWOPSO) to get the optimum response of the investigated system and the results shall be tested to determine which algorithm is the best using (12) "integral square error function (ISE)" as the test equation [16].

$$
\mathrm{F}=\min \left(\int \mathrm{E}_{\mathrm{s}}^{2} \mathrm{dt}+\mathrm{MP}_{\mathrm{P}}\right)
$$

Where $F$ is the fitness function, $e_{s}$ is the speed error and $M_{p}$ is the maximum overshoot.

Figure 4 is showing the complete closed loop control (of a non-linear process) system impeding the optimization algorithm and the ISE. The closed loop PID controller cascaded with the process is tuned for values of $K_{P}, K_{I}$ and $K_{D}$ of each of the HIWOPSO, PSO and IWO algorithms and the numerical results are presented in Table 1. The parameters values of each algorithm including the initialization values (which are chosen in the same range for all algorithms) are shown in Table 2. Optimization Algorithms and inference principles (for FLC) are used to synthesize the ISE and output response to obtain the best values of( $K_{P}, K_{I}$ and $K_{D}$ ) which are used to adjust the PID to control of the marine diesel engine speed. A Matlab/Simulink simulation, shown in Figure 5, is used to simulate the whole system. 


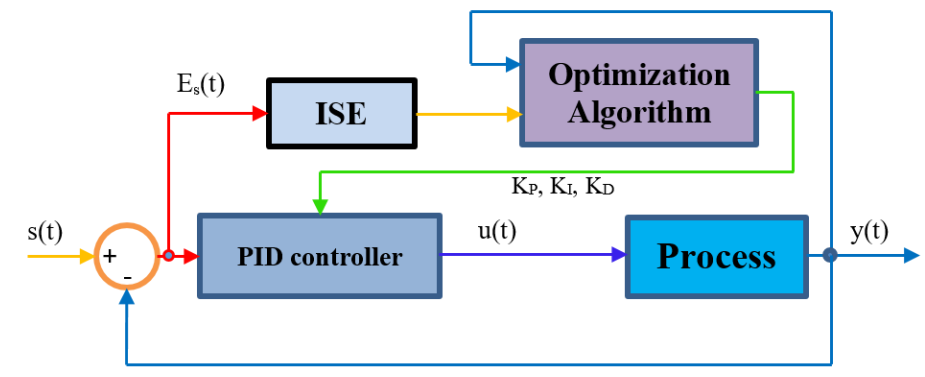

Figure 4. Optimization PID to control the process

Table 1. PID values obtained by each algorithm

\begin{tabular}{cccc}
\hline Algorithms & $\mathrm{Kp}$ & $\mathrm{Ki}$ & $\mathrm{Kd}$ \\
\hline HIWOPSO & 16.9819 & 3.6799 & 3.6969 \\
IWO & 2.7193 & 1.2351 & 0.2611 \\
PSO & 80.0344 & -0.2255 & 11.2859 \\
\hline
\end{tabular}

Table 2. Parameters value of each algorithm

\begin{tabular}{lllll}
\hline Parameter & Definition & PSO & IWO & HIWOPSO \\
\hline $\mathrm{T}$ & Maximum number of iterations & 100 & 100 & 30 \\
N pop & Maximum population size & 30 & 100 & 100 \\
npop0 & Initial population size & - & 10 & 10 \\
Smin & Minimum number of seeds & - & 0 & 0 \\
Smax & Maximum number of seeds & - & 5 & 5 \\
$\mathrm{n}$ & Nonlinear modulation index & - & 2 & 2 \\
oinitial & Standard deviation initial value & - & 1 & 1 \\
ofinal & Standard deviation finial value & - & 0.0001 & 0.0001 \\
c1 & cognitive/local weight & 2 & - & 2 \\
c2 & Social/global weight & 1.8 & - & 2 \\
$\omega$ & Inertia weight & 1 & - & 1 \\
$\Omega$ damp & Inertia weight reduction rate & 0.9 & - & 0.9 \\
\hline
\end{tabular}

Tunable Variables are PID gains, $\mathrm{Kp}$, $\mathrm{Ki}$, and $\mathrm{Kd}$.

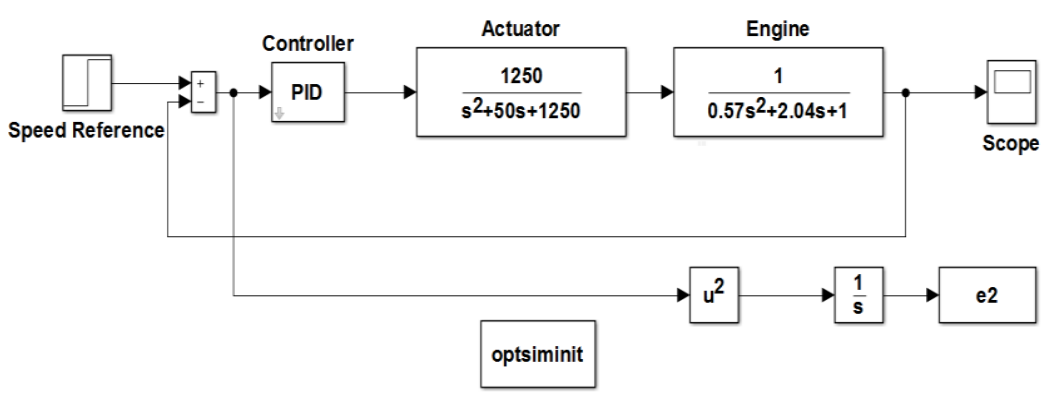

Figure 5. Simulink model of marine diesel engine speed control

\section{RESULTS}

This work is to get the optimum response of the marine diesel engine speed control system through an optimal selection of the PID controller parameters $\left(K_{P}, K_{I}\right.$ and $\left.K_{D}\right)$. The process is accomplished by two steps. The first is to run the used algorithm to find the global optimum values of $\left(K_{P}, K_{I}\right.$ and $\left.K_{D}\right)$ parameters. The second step is to apply these values to the PID controller that controlling the system which is simulated in Figure 5. When each of the three algorithms IWO, PSO and the HIWOPSO were executed; after they randomly initiated with values in the same range as shown in Table 1 the obtained optimum values from each algorithm of $\left(K_{P}, K_{I}\right.$ and $\left.K_{D}\right)$ are shown in Table 1 . These values were fed to the simulation model as shown in Figure 5 and a step-responses for each set of values from each algorithm. The numerical values of the step responses specifications (rise time, overshoot and settling time) are in Table 3. Which also including

Hybrid IWOPSO optimization based marine engine rotational speed control ... (Ahmed Samawi Ghthwan) 
the value of ISE (integral square error) for each algorithm. Table 3. Is also including the corresponding values that obtained using the Fuzzy Logic Control (FLC) technique [16] for the sake of comparison. The graphical responses of the system (the marine diesel engine speed) for the three algorithms and the FLC are in Figure 6.

Table 3. Step response results for each algorithm

\begin{tabular}{ccccccc}
\hline Algorithms & Rise Time & SettlingTime & Overshoot $\%$ & Peak & PeakTime & ISE \\
\hline HIWOPSO & 0.58004 & 3.9417 & 0.1192 & 1.0011 & 2.3314 & 0.1131 \\
IWO & 1.40462 & 6.2935 & 0.1732 & 1.0017 & 3.3555 & 0.5398 \\
PSO & 0.36330 & - & 0 & 0.9957 & 1.4791 & 0.1891 \\
FLC [5] & 2.31199 & 13.2627 & 16.7415 & 1.1674 & 5.4847 & 1.0892 \\
\hline
\end{tabular}

Analyzing the results that shown in Table 3 (and the unit step responses in Figures 6 and 7) which are showing that the HIWOPSO is providing the best response with respect to the other two investigated algorithms and the fuzzy logic. Although, the PSO has encouraging values of rise time and ISE, it is never reached to the final speed, this means that the settling time is infinity when using the PID controller parameters that obtained by this algorithm. It is also clear from the results Table 3 and Figures 6 and 7 that HIWOPSO is giving a better result than that of FLC.

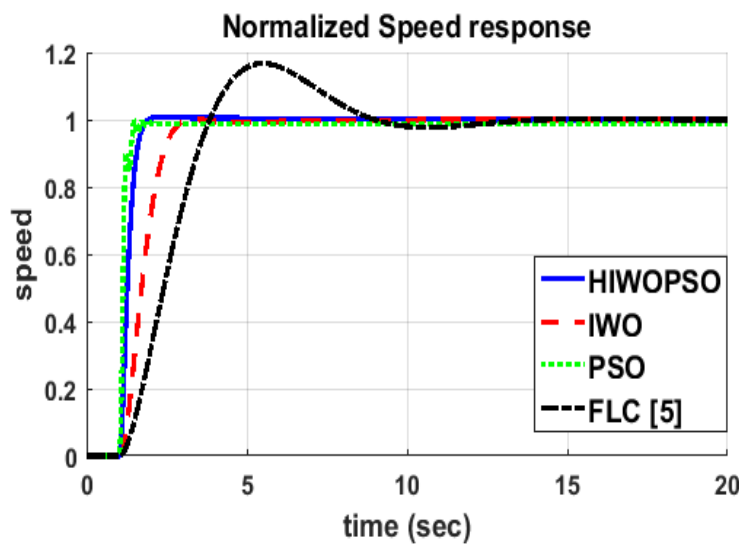

Figure 6. Step response of marine diesel engine speed control

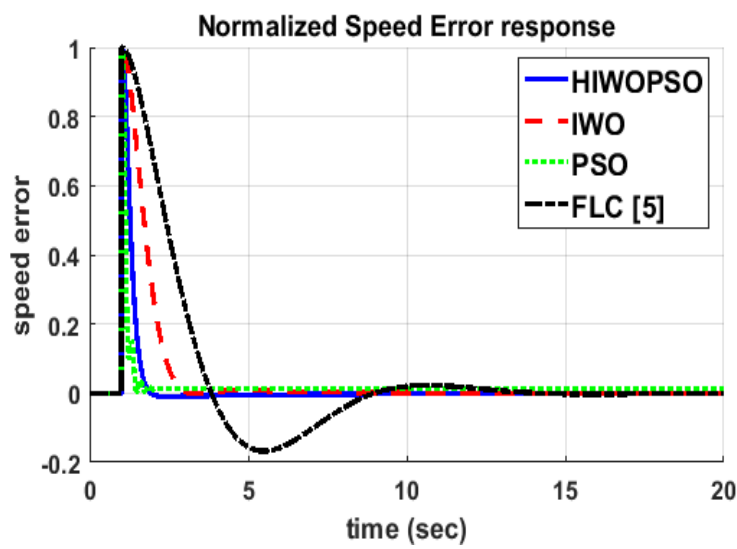

Figure 7. Speed error response of marine diesel engine speed control

\section{CONCLUSION}

HIWOPSO is an algorithm which is a numerical and a randomness behaving. It is a mimic of natural livings' activities such as teeming, cooperative communications, settlements, and competing to get the optimality criterion. In this work HIWOPSO is used to determine the optimum values of the PID controller parameters to optimally control the speed of a marine diesel engine. The investigated system is simulated using MatLab/SimuLink. The efficiency of HIWOPSO is measured by comparing its results with that of widely used latest IWO and PSO evolutionary algorithms and a Fuzzy Logic Control (FLC). This evaluation test is done in two ways, a numerical way by using the Integral Square Error (ISE) function and graphically by analyzing the step response of the system performance. The results are showing that the HIWOPSO algorithm is providing an excellent optimum value for the PID controller parameters. Table 3 showing that ISE having the minimum value when HIWPPSO is used in comparison with the IWO, PSO and FLC. Figures 6 and 7 are showing that when the PID parameters obtained by PSO is having a better step response characteristics but it's never bring the diesel engine to a zero error signal, i.e. the engine speed is not able to reach the desired (set) speed while in the case when the PID parameters deduced by the HIWOPSO are used, the results are better than that of using the parameters obtained by IWO and FLC and the step response is reaching to the case where the actual speed is the same as the setting speed. This means that the HIWOPSO is the best algorithm for the global optimization with respect to IWO, PSO and FLC. It has the capability to come up with non-differentiable objective functions with a multitude number of local optima in a reasonable time limit. This paper is applying the modern control theory to solve one of the difficult 
engineering problems. The optimal estimation of the PID controller parameters becoming easier and accurate to be estimated with a reasonable time period. This shall minimize the hazards and operating errors which are mostly accompanied the estimation of the PID controller when using the conventional control theory.

\section{REFERENCES}

[1] H. W., I. K. M. Steinbuch, L. del Re, Optimization and optimal control in automotive systems, Springer International Publishing Switzerland, 2014.

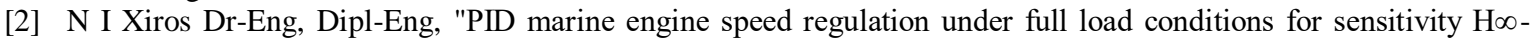
norm specifications against propeller disturbance," Journal of Marine Engineering \& Technology, vol. 2004(5), pp. 3-11, 2004.

[3] Tadeusz Borkowski, Lech Kasyk, Przemyslaw Kowalak, "Assessment of ship's effective power fuel consumption and emission using the vessel speed," Journal of KONES Powertrain and Transport, vol 18, no. 2, 2011.

[4] M. Guzelkaya, I. Eksin, E. Yesil, "Self-tuning of PID type fuzzy logic controller coefficients via relative rate observer," Engineering Applications of Artificial Intelligence, vol. 16, pp. 227-236, 2003.

[5] Tien Anh Tran, Xinping Yan, and Yupeng Yuan, "Marine engine rotational speed control automatic system based on fuzzy PID logic controller," International Conference on Transportation Information and Safety (ICTIS), Banff, Canada, 2017.

[6] J.G.Ziegler and N.B Nichols, "Process lags in automatic control circuit," ASME transaction, pp. 433-444, 1943.

[7] J.G.Ziegler and N.B Nichols, "Opimum setting for automatic controller," ASME transaction, pp. 759-768, 1942.

[8] A.M.Lopes, J.A.Miller, C.L. Smith, and P.W.Muller, "Tuning controller with error-integral criteria," Instument Technology, vol. 3, pp. 57-62, 1976.

[9] A.M.Zhung, A. D.P, "Automatic tuning of optimum pid controller," IEEE Control Systems Magazine, vol. 3, pp. 216-224, 1993.

[10] Dorigo and Blum, "Ant colony optimization theory: A survey," TCS: Theoretical Computer Science, vol. 345, 2005.

[11] M. Dorigo, G. D. Caro, and L. M. Gambardella, "Ant algorithms for discrete optimization," Artificial Life, vol. 5, no. 2, pp. 137-172, 1999.

[12] M. Farooq, "From the wisdom of the hive to intelligent routing in telecommunication networks," Feb. 012006. [Online].

[13] J. Kennedy and R. C. Eberhart, "Particle swarm optimization," in Proc. of the IEEE Int. Conf. on Neural Networks. Piscataway, NJ: IEEE Service Center, pp. 1942-1948, 1995.

[14] R. C. Eberhart, "Computational intelligence: a perspective," in Evolutionary Programming, pp. 239-245, 1996.

[15] Hossein Hajimirsadeghi, Caro Lucas, "A hybrid IWO/PSO algorithm for fast and global optimization," IEEE EUROCON, Russia, May 2009.

[16] Z. Hosseini , A. Jafarian, "A hybrid algorithm based on invasive weed optimization and particle swarm optimization for global optimization," (IJACSA) International Journal of Advanced Computer Science and Applications, vol. 7, no. 10, 2016.

[17] Y. Shi and R. C. Eberhart, "A modified particle swarm optimizer," in Proc. IEEE Int. Conference on Evolutionary Computation, Piscataway, NJ, pp. 69-73, 1998.

[18] R.C. Eberhart, P. Simpson, and R. Dobbins, Computational intelligence PC tools, Academic Press Professional, San Diego, CA, pp. 212-226, 1996.

[19] R. Mehrabian and C. Lucas, "A novel numerical optimization algorithm inspired from weed colonization," Ecological Informatics, vol. 1, pp. 355-366, 2006.

[20] Tumari, M.Z.M., Abidin, A.F.Z., Hussin, M.S.F., Kadir, A.M.A., Aras, M.S.M. and Ahmad, M.A., "PSO fine-tuned model-free PID controller with derivative filter for depth control of hovering autonomous underwater vehicle," In Proceedings of the 10th National Technical Seminar on Underwater System Technology 2018, Springer, Singapore, pp. 3-13, 2018

[21] Khanduja, N. and Bhushan, B., "CSTR control using IMC-PID, PSO-PID, and hybrid BBO-FF-PID controller," in Applications of Artificial Intelligence Techniques in Engineering 2019, Springer, Singapore, pp. 519-526, 2019.

[22] Ahmed J. Ali, Ziyad K. Farej, Nashwan S. Sultan., "Performance evaluation of a hybrid fuzzy logic controller based on genetic algorithm for three phase induction motor drive" International Journal of Power Electronics and Drive System (IJPEDS), vol. 10, no. 1, pp. 117-127, 2019.

[23] Hadeel N. Abdullah., "A hybrid bacterial foraging and modified particle swarm optimization for model order reduction," International Journal of Electrical and Computer Engineering (IJECE), vol. 9, no. 2, pp. 1100-1109, 2019.

[24] P. Lokender Reddy, G. Yesuratnam., "A modified bacterial foraging algorithm based optimal reactive power dispatch," Indonesian Journal of Electrical Engineering and Computer Science (IJEECS), vol. 13, no. 1, pp. 361367, 2019.

[25] Aras, M.S.M., Abdullah, S.S., Othman, S.Y., Sulaiman, M., Basar, M.F., Zambri, M.K.M., Kamarudin, M.N." Fuzzy logic controller for depth control of underwater remotely operated vehicle". J. Theor. Appl. Inf. Tech. 91(2), 275-288 (2016) 


\section{BIOGRAPHIES OF AUTHORS}

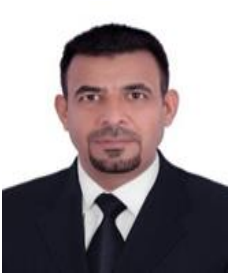

Mr. Ahmed Samawi Ghthwan earned his M.sc in the field of Electrical and Electronic Engineering from Eastern Mediterranean University, Turkey / North Cyprus 2013. He has more than five years of experience in teaching. He completed his BSc in Electrical Engineering, university of technology, Baghdad, Iraq, 2001. His research interests includes power electronics, control power system, electronic system design and predictive current control modeling

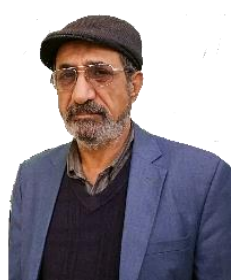

Mr. Abdulrasul A. Al-hayder earned his master degree in control and instrumentation in 1985 and bachelor degree in 1981 from the University Of Technology, Baghdad/ Iraq. He has a teaching experience for more than tweenty years. He is interesting in the automatic control systems engineering, systems engineering, and communications as digital techniques fields.

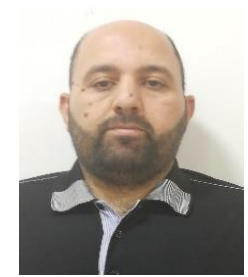

Ali Shaban Hassooni, he born in Babil, Iraq 1981. He achieved B.S.c. since 2003 in Electrical Engineering, College of Engineering, Universty of Babylon, Iraq and He achieved M.S.c. in Electronics and Communication field since 2010 in Electrical Engineering, College of Engineering, Universty of Babylon, The main interested field is designing of electronics system and robotics fileld. He is a Lecturer in Electrical Engineering Department, College of Engineering, Babylon University, Iraq. 